\title{
Avaliação da aplicação de cinzas pesadas de termelétrica em blocos intertravados de concreto para pavimentos
}

\section{Evaluation of the application of bottom ashes from thermoelectric in concrete blocks for pavements}

\author{
Webert Brasil Cirilo da Silva ${ }^{1}$, Suelly Helena de Araújo Barroso ${ }^{1}$, \\ Antônio Eduardo Bezerra Cabral ${ }^{2}$
}

\footnotetext{
${ }^{1}$ Programa de Pós-Graduação em Engenharia de Transportes, Universidade Federal do Ceará - PETRAN/UFC, Rua Armando Farias, Bloco 703, Campus do Pici, Fortaleza, Ceará, Brasil. e-mail: webertcirilo@ hotmail.com, suelly@det.ufc.br

${ }^{2}$ Programa de Pós-Graduação em Engenharia Civil: Estruturas e Construção Civil, Universidade Federal do Ceará PEC/UFC, Acesso Público, Bloco 733, Campus do Pici, Fortaleza, Ceará, Brasil.

e-mail: eduardo.cabral@ufc.br
}

\section{RESUMO}

Tendo em vista a grande geração de cinzas pesadas advindas de uma usina termoelétrica, decidiu-se verificar a incorporação das mesmas no concreto usado em blocos intertravados para pavimentação. Depois da coleta de os materiais convencionais (cimento e agregados naturais) e alternativos (cinzas pesadas), foram realizados ensaios ambientais (extrato lixiviado e solubilizado) nas cinzas e ensaios de caracterização física (análise granulométrica, densidade real, limites de liquidez e de plasticidade e umidade higroscópica) em todos os agregados. Por meio de estabilizações granulométricas, foram originados dois traços alternativos com cinzas e um de referência com agregados convencionais. Em todos os concretos, foi determinado, no estado fresco, $\mathrm{o}$ abatimento do tronco de cone e, no estado endurecido, foram realizados ensaios de resistência à compressão e de absorção de água. Moldaram-se ainda pavers tipo I (formato retangular) com dimensões de $10 \mathrm{~cm} \div$ $20 \mathrm{~cm} \div 6 \mathrm{~cm}$ (largura $\div$ comprimento $\div$ espessura), os quais foram ensaiados, quanto à resistência à compressão. Também se procedeu ao dimensionamento, através de métodos empíricos, de um pavimento intertravado idealizado com as misturas investigadas. Pode-se constatar que, no ensaio de absorção de água, os três traços estudados apresentaram resultados médios abaixo do valor máximo de $6 \%$, o que está de acordo com as normativas. Com relação ao ensaio de resistência à compressão, os resultados são inferiores ao mínimo de $35 \mathrm{MPa}$, porém é possível destinar os pavers a áreas de menor solicitação de tráfego, como ciclovias. Conclui-se que os resultados obtidos, a partir do programa experimental, demonstram que o emprego das cinzas pesadas em pavimentos intertravados de concreto apresenta potencial a ser explorado para fins de comercialização.

Palavras-chave: Cinzas pesadas. Termoelétrica. Blocos intertravados. Pavimentação. Estabilizações.

\begin{abstract}
Considering the great generation of bottom ashes coming from a thermoelectric plant, it was decided to verify the incorporation of the same in the concrete used in interlocking blocks for paving. After the collection of conventional (cement and natural aggregates) and alternative (bottom ashes) materials, environmental tests (leached and solubilized extract) were performed on the ashes and physical characterization tests (particle size analysis, real density, liquidity and plasticity limits and hygroscopic humidity) in all aggregates. By means of granulometric stabilizations, two alternative traces with ash and one reference with conventional aggregates were prepared. In all concretes, the slump value was determined in the fresh state and, in the hardened state, compressive strength and water absorption tests were performed. Pavers type I (rectangular shape) with dimensions of $10 \mathrm{~cm} \div 20 \mathrm{~cm} \div 6 \mathrm{~cm}$ (width $\div$ length $\div$ thickness) were molded and tested for
\end{abstract}


compressive strength. An empirical method was also used to design an interlocking pavement designed with the mixtures investigated. It can be seen that, in the water absorption test, the three traces studied presented average results below the maximum value of $6 \%$, which is in accordance with the regulations. With respect to the compressive strength tests, the results are lower than the minimum of $35 \mathrm{MPa}$, however it is possible to target the pavers to areas of lower traffic demand, such as bike paths. It is concluded that the results obtained, from the experimental program, demonstrate that the use of bottom ashes on interlocking concrete pavements presents potential to be exploited for commercialization purposes.

Keywords: Bottom ashes. Thermoelectric. Interlocking blocks. Paving. Stabilizations.

\section{INTRODUÇÃO}

Um pavimento pode apresentar diversos tipos de materiais na sua constituição, como areia em suas camadas granulares e compostos asfálticos em seu revestimento. Com relação ao uso de materiais, um tema importante de pesquisa é o aproveitamento de resíduos, os quais podem ser advindos de parques industriais, para o uso nas camadas dos pavimentos. Muitas dessas instalações, por apresentarem um grande porte, geram toneladas de resíduos que são dispostos a céu aberto diversas vezes, ocasionando problemas ambientais. Dessa forma, esses mesmos resíduos podem ser usados como matéria-prima em obras de engenharia, a fim de se atribuir uma finalidade útil para os mesmos.

No Brasil, as reservas de carvão mineral são estimadas em 32 bilhões de toneladas, em que, na região Sul do país, o estado do Rio Grande do Sul concentra 89\% do total nacional e o estado de Santa Catarina contém cerca de $10 \%$ [1]. Dessa forma, a produção de cinzas no sul do Brasil apresentou uma evolução desde a década de 1920, chegando à geração significativa de 4 milhões de toneladas de cinzas no ano 2000 [2].

No estado do Ceará, situado na região Nordeste do Brasil, está localizado o Complexo Industrial e Portuário do Pecém (CIPP) que contém as Usinas Termelétricas Pecém I e Pecém II, e essas geram, em conjunto, de 1200 a 1350 toneladas de cinzas diariamente [3]. Devido a essa considerável produção, o espaço disponível para o armazenamento desse material está cada vez menor, aliado aos custos do processo de estocagem. Isso pode ser considerado uma problemática atual que tem mobilizado esforços para estudar uma forma ambiental e economicamente viável para a disposição dessas cinzas.

É importante destacar que, na produção das cinzas, durante o processo de geração de energia da usina com a combustão do carvão, cerca de $40 \%$ dos resíduos correspondem à fração das cinzas, sendo que $40 \%$ dessa fração consiste em cinza pesada (bottom ash) [1]. No que diz respeito à destinação das cinzas pesadas, por essas possuírem uma granulometria mais grossa, acabam caindo para o fundo das fornalhas e de gaseificadores, de onde são retiradas por fluxo de água. Apesar de as mesmas passarem por um sistema de redução do tamanho de suas partículas, o destino final desse material ainda continua sendo depósitos a céu aberto, agredindo o ecossistema local [4].

A partir de estudos de laboratório e experimentos de campo, tem sido demonstrado o potencial das cinzas como materiais para a construção de pavimentos, elementos de alvenaria, aterros estruturais, dormentes de vias férreas, bem como matérias-primas para a extração de novos produtos, como zeólitas [5]. Apesar da possiblidade de aplicação em diferentes campos, estima-se que apenas $40 \%$ da cinza volante (fly ash) produzida no estado do Rio Grande do Sul é reutilizada, sendo absorvida pela indústria cimenteira principalmente [5]. É importante mencionar o Complexo Termelétrico Jorge Lacerda, localizado no estado de Santa Catarina, que se destaca no reaproveitamento dos resíduos, uma vez que $100 \%$ das cinzas volantes produzidas são absorvidas pelas indústrias cimenteiras. Já as cinzas pesadas são armazenadas em bacias de decantação localizadas no interior do complexo [5]. Com relação às Usinas Termelétricas Pecém I e Pecém II, das cinzas volantes produzidas, $40 \%$ são destinadas a indústria cimenteira da região e $60 \%$ são armazenadas no pátio da própria usina [1].

No que diz respeito à definição de pavimento intertravado, segundo a norma NBR 9781:2013 [6] da Associação Brasileira de Normas Técnicas (ABNT), essa estrutura é do tipo flexível. Pode-se colocar que as camadas pertencentes a esse pavimento são: reforço do subleito (opcional), sub-base, base, camada de areia de assentamento e revestimento, o qual é constituído pelo Bloco Intertravado de Pavimento (BIP) e pelo material de rejuntamento. O revestimento e a camada de assentamento são contidos lateralmente, em geral, pelo meio-fio. A Figura 1 (criação dos autores) representa a estrutura típica de um pavimento intertravado. 


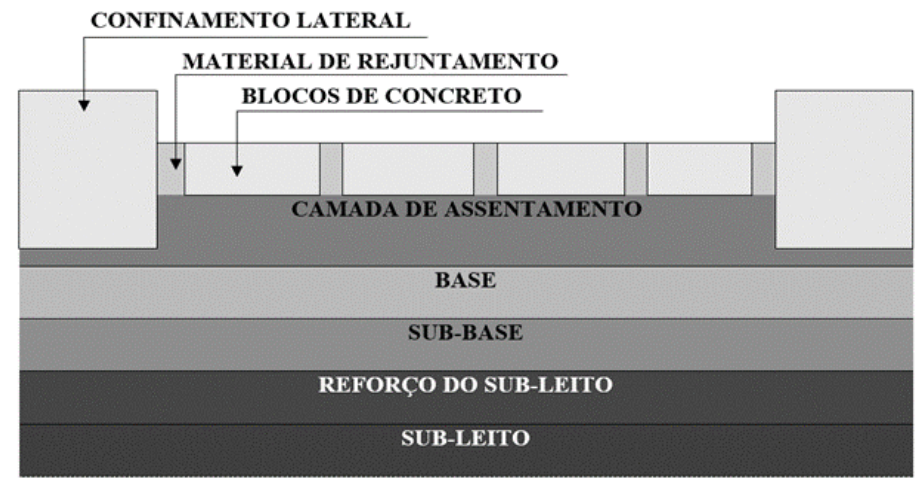

Figura 1: Perfil das camadas do pavimento intertravado.

Atualmente, é interessante destacar que o uso de pavimentos intertravados é bastante difundido em países europeus e pode ser conferido na Alemanha principalmente, que é o maior produtor mundial de paver, com mais de 200 milhões de metros quadrados por ano [7]. Na Holanda, provavelmente o segundo maior polo no mundo, foi criada uma peça que absorve a poluição do ar, chamada de paver fotocatalítico, que recebe uma pintura de dióxido de titânio para possuir essa propriedade [7]. Além disso, estudos feitos na Índia estão avaliando a influência de bactérias, como a Bacillus pasteurii, nas propriedades mecânicas no concreto usado em blocos paver. Esses organismos, no caso, podem produzir carbonato de cálcio $\left(\mathrm{CaCO}_{3}\right)$, o qual melhora a durabilidade e a resistência do concreto [8].

No que se refere à utilização das cinzas, um dos processos alternativos é a fabricação do BIP, sendo que o concreto utilizado nesses blocos é composto por materiais convencionais, como brita, areia e cimento. Dessa forma, existe a possibilidade de as cinzas substituírem algum desses componentes, desde que sejam feitos os estudos necessários. Com relação à possibilidade do uso de resíduos na composição dos blocos de concreto, existem diversos agregados alternativos testados para esse fim. No âmbito nacional, como exemplo, podem ser citadas as pesquisas de SOUZA [9], em que foi testada a adição de resíduos de óxido de alumínio (sínter) na composição do concreto, e o estudo de GUERRA [10], em que foi adicionado minério de ferro. Já no âmbito internacional, outros autores analisaram a incorporação dos seguintes materiais: fibra de aço [11]; agregado reciclado de Resíduo de Construção e Demolição (RCD) [12] e agregados provenientes da reciclagem de blocos danificados [13].

No que se refere ao escopo internacional, no trabalho de ERANDI et al. [14], foi testada a inserção de cinza pesada, proveniente de usina termelétrica, no concreto utilizado em BIPs. Foram utilizados cinco traços, sendo um de referência e quatro alternativos, e as cinzas substituíram a areia de rio (agregado fino) nos teores de 25\%, 50\%, 75\% e 100\% em massa. No ensaio de Resistência à Compressão Simples (RCS) aos 28 dias, pôde-se observar que os concretos alternativos apresentaram valores inferiores, com relação ao traço de referência, porém o resultado do teor de $25 \%$ permitiu que os blocos fossem aprovados nas especificações, o que valoriza essa substituição parcial. De qualquer forma, o motivo do decréscimo no valor da RCS pode estar relacionado com o fato da cinza pesada ser um material granular mais grosseiro, com relação à areia de rio, o que pode provocar uma ligação mais fraca do resíduo com os componentes do concreto.

Outro trabalho inserido no escopo internacional é a pesquisa de SENARATNA et al. [15], em que também foi testada a inserção de cinza pesada no concreto utilizado em BIPs. Nesse caso, foram testados três traços, sendo um de referência e dois alternativos, e as cinzas substituíram a areia de rio (agregado fino) nos teores de $10 \%$ e $20 \%$ em massa. No ensaio de RCS aos 28 e 56 dias, pôde-se observar que os concretos alternativos apresentaram valores inferiores, com relação ao traço de referência, porém os resultados dos teores de $10 \%$ e $20 \%$ permitiram que os blocos fossem aprovados nas especificações. Além disso, a utilização das cinzas pesadas proporcionou um menor custo de fabricação do bloco paver. Nessa pesquisa, o motivo do decréscimo no valor da RCS pode estar relacionado com o fato da cinza pesada não ser um material tão resistente, quanto à areia de rio, o que pode fazer o concreto não suportar cargas significativas.

É importante destacar que, aliado ao uso das cinzas, o pavimento intertravado necessita estar bem dimensionado para a estrutura ser viável do ponto de vista técnico. Segundo CRUZ [16], a maioria dos métodos são criados a partir de adaptações da metodologia aplicada para pavimentos flexíveis. Por exemplo, nos Estados Unidos, a National Concrete Masonry Association (NCMA), aplicou mudanças no método de dimensionamento de pavimentos flexíveis da American Association of State Highway of Transportation Officials (AASHTO) para utilização em pavimentos intertravados. Também pode-se colocar que HUURMAN [17] 
propôs um método de dimensionamento baseado na deformação permanente transversal e longitudinal nas camadas de base e de assentamento, considerando a contribuição de todos os componentes do pavimento. Outro trabalho foi o de BABA et al. [18], em que foram realizados trabalhos com o uso de equipamentos de medição de deflexão em campo, conhecidos como Falling Weight Defletometer (FWD). O estudo mostrou que esse tipo de instrumento pode ser eficaz na avaliação sistemática de pavimentos intertravados no campo, permitindo a determinação dos módulos de elasticidade por processo de retroanálise.

Dessa forma, o objetivo deste artigo é avaliar o uso de cinzas pesadas, advindas de usina termelétrica, do ponto de vista técnico e ambiental, na composição do concreto usado em BIPs.

\section{MATERIAIS E MÉTODOS}

Foram utilizados os seguintes materiais: cinzas pesada da combustão de carvão mineral, britas fonolíticas de dimensões 19,0 mm e 12,5 mm, cimento CP V - Alta Resistência Inicial (ARI), água da rede pública de distribuição (a mesma atende aos requisitos exigidos pela ABNT NBR 15900-1:2009 [19]), areia natural quartzosa de leito de rio e areia britada, oriunda do processo de britagem dos agregados graúdos. As cinzas foram coletadas na Usina Termelétrica do Pecém (UTP). Os agregados e o cimento foram obtidos no mercado local.

\subsection{Primeira etapa metodológica}

Foram contemplados os ensaios de caracterização a serem realizados nas cinzas pesadas e nos agregados naturais, conforme metodologia estabelecida em normas da ABNT e do Departamento Nacional de Infraestrutura de Transportes (DNIT). As Tabelas 1 e 2 mostram, respectivamente, os ensaios realizados nas cinzas e nos materiais convencionais, como também, as normas vigentes de cada procedimento. Para efeito de informação, é importante colocar que o ensaio de solubilização avalia o potencial do resíduo de liberar seus componentes constituintes para a água pura, comparativamente ao padrão de potabilidade [1]. Já o ensaio de lixiviação avalia a capacidade de o resíduo liberar parte dos seus componentes para o meio ambiente, verificando seu potencial de impactar solos e águas subterrâneas [1].

Tabela 1: Ensaios realizados nas cinzas com as suas normas vigentes.

\begin{tabular}{l|l}
\hline ENSAIOS & NORMAS VIGENTES \\
\hline Preparação de amostras para ensaios de caracterização & DNER - ME 041:1994 [20] \\
\hline Análise granulométrica & DNER - ME 051:1994 [21] \\
\hline Limite de plasticidade & DNER - ME 082:1994 [22] \\
\hline Densidade real & DNER - ME 093:1994 [23] \\
\hline Limite de liquidez & DNER - ME 122:1994 [24] \\
\hline Extrato lixiviado & ABNT NBR 10005:2004 [25] \\
\hline Extrato solubilizado & ABNT NBR 10006:2004 [26] \\
\hline Massa específica para agregado graúdo & ABNT NBR NM 53:2009 [27] \\
\hline Massa específica para agregado miúdo & ABNT NBR NM 52:2003 [28] \\
\hline Massa unitária & ABNT NBR NM 45:2006 [29] \\
\hline
\end{tabular}

Tabela 2: Ensaios realizados nos agregados com as suas normas vigentes.

\begin{tabular}{l|l}
\hline ENSAIOS & NORMAS VIGENTES \\
\hline Massa específica para agregado graúdo & ABNT NBR NM 53:2009 [27] \\
\hline Massa específica para agregado miúdo & ABNT NBR NM 52:2003 [28] \\
\hline Massa unitária & ABNT NBR NM 45:2006 [29] \\
\hline Composição granulométrica & ABNT NBR NM 248:2003 [30] \\
\hline
\end{tabular}

\subsection{Segunda etapa metodológica}

Foram realizadas as misturas dos materiais para a produção do concreto e, no caso, foram utilizados um traço de referência com materiais convencionais, o qual é adotado por uma empresa especializada em fabricar blo- 
cos intertravados, e três traços alternativos com o uso das cinzas. É importante destacar que, de acordo com a norma ABNT NBR 9781:2013 [6], é necessário que a peça de concreto apresente uma resistência característica à compressão mínima de $35 \mathrm{MPa}$ aos 28 dias de cura e uma absorção de água média inferior a $6 \%$. Dessa forma, a estabilização granulométrica é a técnica utilizada de forma a inserir as cinzas pesadas na composição do concreto, de modo a tentar enquadrá-las nas especificações construtivas vigentes.

Na composição dos traços alternativos, decidiu-se avaliar o efeito individual que a cinza teria ao substituir cada um dos agregados convencionais, assim, poderia ser descoberta qual substituição é a mais benéfica do ponto de vista mecânico para o concreto. Dessa forma, a cinza pesada foi separada em duas porções, sendo que a cinza grossa (passante na peneira de $19,0 \mathrm{~mm}$ e retida na de 2,0 mm) substituiu $10 \%$ da massa de brita 19,0 mm, enquanto a cinza fina (passante na peneira de 2,0 $\mathrm{mm}$ ) substituiu $10 \%$ da massa de areia. A Tabela 3 ilustra, para cada traço, os consumos por unidade de volume de cada um dos materiais componentes do concreto.

Tabela 3: Consumos por $\mathrm{m}^{3}$ dos materiais na composição dos traços.

\begin{tabular}{l|l|l|l|l|l|l|l|l}
\hline TRAÇO & $\begin{array}{l}\text { CIMENTO } \\
\left(\mathbf{k g} / \mathbf{m}^{3}\right)\end{array}$ & $\begin{array}{l}\text { AREIA } \\
\text { NATURAL } \\
\left(\mathbf{k g} / \mathbf{m}^{3}\right)\end{array}$ & $\begin{array}{l}\text { AREIA } \\
\text { BRITADA } \\
\left(\mathbf{k g} / \mathbf{m}^{3}\right)\end{array}$ & $\begin{array}{l}\text { BRITA } \\
\mathbf{1 2 , 5} \\
\mathbf{m m} \\
\left(\mathbf{k g} / \mathbf{m}^{3}\right)\end{array}$ & $\begin{array}{l}\text { BRITA } \\
\mathbf{1 9 , 0} \\
\mathbf{m m} \\
\left(\mathbf{k g} / \mathbf{m}^{3}\right)\end{array}$ & $\begin{array}{l}\text { CINZA } \\
\text { GROSSA } \\
\left(\mathbf{k g} / \mathbf{m}^{3}\right)\end{array}$ & $\begin{array}{l}\text { CINZA } \\
\text { FINA } \\
\left(\mathbf{k g} / \mathbf{m}^{3}\right)\end{array}$ & $\begin{array}{l}\text { ÁGUA } \\
\left(\mathbf{k g} / \mathbf{m}^{3}\right)\end{array}$ \\
\hline Ref. & 279,95 & 652,43 & 652,43 & 551,34 & 126,10 & 0 & 0 & 238,49 \\
\hline Alt. 1 & 279,95 & 652,43 & 652,43 & 551,34 & 113,49 & 12,61 & 0 & 238,49 \\
\hline Alt. 2 & 277,16 & 581,33 & 581,33 & 545,84 & 124,84 & 0 & 129,18 & 261,56 \\
\hline
\end{tabular}

É interessante colocar que, apesar da pouca diferença entre as quantidades de água e de cimento nos traços, os consumos significativos das areias presentes fazem o concreto permanecer em estado seco. Logo após a mistura dos materiais na betoneira, o concreto, ainda fresco, foi submetido ao ensaio de abatimento do tronco de cone, destacando o fato de que esse processo foi feito na preparação dos três traços estudados. Pelo fato de se estar trabalhando com concreto seco nas três ocasiões, o abatimento foi zero. Dessa forma, decidiuse usar o método de adensamento mecânico com o aparelho vibrador, o qual acreditou-se ser mais eficiente na retirada dos vazios do concreto.

Uma observação importante a ser feita a respeito do concreto no estado fresco é que, pelo mesmo se tratar de um tipo seco, é recomendável a realização do ensaio de determinação da consistência do concreto pelo consistômetro "VeBe", regido pela norma DNIT- ME 064:2004 [31]. Esse método mede o tempo necessário, para que um tronco de cone de concreto fresco amolde-se a um cilindro, sob ação de vibração padronizada. O problema é que esse aparelho se encontra, somente, no Instituto Federal de Educação, Ciência e Tecnologia do Ceará (IFCE) no Campus de Fortaleza e por questões de tempo com o transporte de equipamento e de material entre a Universidade Federal do Ceará (UFC) e o IFCE, decidiu-se não realizar esse ensaio.

Foram utilizados moldes cilíndricos de $10 \mathrm{~cm}$ de diâmetro por $20 \mathrm{~cm}$ de altura e fôrmas para pavers tipo I (formato retangular) com dimensões de $10 \mathrm{~cm} \div 20 \mathrm{~cm} \div 6 \mathrm{~cm}$ (largura $\div$ comprimento $\div$ espessura). Os ensaios realizados e suas respectivas normas estão apresentados na Tabela 4.

Tabela 4: Ensaios no concreto com as suas normas vigentes.

\begin{tabular}{l|l}
\hline ENSAIOS & NORMAS VIGENTES \\
\hline $\begin{array}{l}\text { Resistência à compressão para } \\
\text { Corpo-de-Prova (CP) cilíndrico }\end{array}$ & ABNT NBR 5739:2007 [32] \\
\cline { 1 - 1 } $\begin{array}{l}\text { Abatimento do tronco de cone } \\
\text { (slump test) no concreto fresco }\end{array}$ & ABNT NBR NM 67:1998 [33] \\
\cline { 1 - 2 } $\begin{array}{l}\text { Resistência à compressão para } \\
\text { paver }\end{array}$ & ABNT NBR 9781:2013 [6] \\
\cline { 1 - 2 } Absorção de água & \\
\hline
\end{tabular}

Pode-se destacar que, para o ensaio de RCS, os períodos de cura foram de 3, 7 e 28 dias, sendo testa- 
dos três CP's cilíndricos e dois blocos para cada período e traço. No caso dos testes aos 3 e 7 dias de cura, os mesmos foram considerados, pois a norma ABNT NBR 9781:2013 [6] informa que os blocos de concreto podem apresentar resistência mínima à compressão de pelo menos $80 \%$ de $35 \mathrm{MPa}(28 \mathrm{MPa})$, o que torna a especificação menos rigorosa. No teste de absorção de água, as amostras foram retiradas depois de 28 dias submersas, em que foram testados três CP's cilíndricos para cada traço. As equações necessárias para a determinação da RCS e absorção de água para CP's cilíndricos e pavers estão disponíveis nas normas ABNT NBR 5739:2007 [32] e ABNT NBR 9781:2013 [6]. É importante destacar que a RCS média foi determinada para os CP's cilíndricos, enquanto a RCS característica foi calculada para os blocos paver.

\subsection{Terceira etapa metodológica}

Por meio das misturas utilizadas para a produção do concreto, procedeu-se para o dimensionamento de um pavimento intertravado a ser construído em uma área de estacionamento, com cerca de $1624 \mathrm{~m}^{2}$.

Foi realizado um pré-dimensionamento pelo procedimento empírico do ET-27 da Associação Brasileira de Cimento Portland (ABCP) [34], pois se trata de uma área de estacionamento, onde trafegam veículos de pequeno porte geralmente, como automóveis e motocicletas. Decidiu-se que o tráfego atuante na região seria leve com o número "N" (número de operações do eixo simples padrão com rodas duplas e carregamento de 8,2 tf) igual a $3 \times 10^{5}$. Com relação às camadas granulares do pavimento, adotaram-se os materiais considerados no trabalho de VASCONCELOS [1].

\section{RESULTADOS E DISCUSSÃO}

\subsection{Resultados e discussão dos ensaios de caracterização da cinza e dos agregados}

As Tabelas 5 e 6 apresentam os resultados dos ensaios ambientais realizados na cinza pesada.

Tabela 5: Resultados do extrato lixiviado.

\begin{tabular}{l|l|l|l|l}
\hline FLUORETO & $\begin{array}{l}\text { CLORETO } \\
\mathbf{F}^{-}\end{array}$ & $\begin{array}{l}\text { NITRATO } \\
\mathbf{C l}^{-}\end{array}$ & $\begin{array}{l}\text { SULFATO } \\
\mathbf{N O}_{\mathbf{3}}^{-} \\
(\mathbf{m g} / \mathbf{L})\end{array}$ & $\begin{array}{l}\mathbf{S O}_{4}{ }^{2-} \\
(\mathbf{m g} / \mathbf{L})\end{array}$
\end{tabular}

Tabela 6: Resultados do extrato solubilizado.

\begin{tabular}{l|l|l|l|l|l|l|l}
\hline & $\begin{array}{l}\text { FLUORETO } \\
\mathbf{F}^{-} \\
(\mathbf{m g} / \mathbf{L})\end{array}$ & $\begin{array}{l}\text { CLORETO } \\
\mathbf{C l}^{-} \\
(\mathbf{m g} / \mathbf{L})\end{array}$ & $\begin{array}{l}\text { NITRITO } \\
\mathbf{N O}^{-} \\
(\mathbf{m g} / \mathbf{L})\end{array}$ & $\begin{array}{l}\text { BROMETO } \\
\mathbf{B r}^{-} \\
(\mathbf{m g} / \mathbf{L})\end{array}$ & $\begin{array}{l}\text { NITRATO } \\
\mathbf{N O}_{3}{ }^{-} \\
(\mathbf{m g} / \mathbf{L})\end{array}$ & $\begin{array}{l}\text { FOSFATO } \\
\mathbf{P O}_{4}{ }^{3-} \\
(\mathbf{m g} / \mathbf{L})\end{array}$ & $\begin{array}{l}\text { SULFATO } \\
\mathbf{S O}_{4}{ }^{2-} \\
(\mathbf{m g} / \mathbf{L})\end{array}$ \\
\hline Amostra & 1,74 & 8,04 & 0,58 & 1,59 & 1,06 & 2,76 & 426,63 \\
\hline Limite & 1,50 & 250,00 & - & - & 10,00 & - & 250,00 \\
\hline
\end{tabular}

De acordo com a Tabela 5, pode-se perceber que somente um composto dos quatro detectáveis possui valor limite presente na norma ABNT NBR 10005:2004 [25]. No caso, a cinza pesada apresenta uma concentração do ânion fluoreto acima do permitido, o que é suficiente para classificar o resíduo como Classe I (perigoso). Esse resultado mostra a necessidade de cuidados no que se refere à destinação final dessas cinzas e à sua utilização, porém, para que o uso do resíduo não seja inviabilizado do ponto de vista ambiental, precisam ser feitas algumas considerações.

Na Tabela 6, primeiramente, pode-se perceber que a cinza pesada possui as concentrações dos ânions fluoreto e sulfato acima do permitido, com isso, sem levar em conta os resultados do extrato lixiviado, o resíduo seria classificado como Classe II A (não inerte). É importante destacar que, segundo LOPES et al. [35], o fato de a cinza ser um resíduo não inerte não reprova a sua utilização na pavimentação.

De acordo com VASCONCELOS [2], a tecnologia de encapsulamento de contaminantes, também conhecida como método de estabilização, vem se tornando uma boa alternativa para tratar resíduos perigosos e gerenciá-los de forma segura e eficaz, melhorando suas características toxicológicas. Conforme BAIRD [36], 
o cimento Portland é frequentemente utilizado como estabilizante, em que o mesmo diminui a solubilidade dos contaminantes. Além disso, a compactação pode funcionar como uma forma de encapsular os resíduos.

Os ensaios de caracterização física das cinzas estão apresentados na Tabela 7.

Tabela 7: Resultados dos ensaios de caraterização física para as cinzas pesadas.

\begin{tabular}{l|l|l|l|l}
\hline & $\begin{array}{l}\text { DENSIDADE } \\
\text { REAL }\end{array}$ & $\begin{array}{l}\text { LIMITE DE } \\
\text { LIQUIDEZ (\%) }\end{array}$ & $\begin{array}{l}\text { LIMITE DE } \\
\text { PLASTICIDADE (\%) }\end{array}$ & $\begin{array}{l}\text { UMIDADE } \\
\text { HIGROSCÓPICA (\%) }\end{array}$ \\
$\begin{array}{l}\text { Cinzas } \\
\text { pesadas }\end{array}$ & 2,35 & Não- Plástico (NP) & NP & 0,1 \\
\hline
\end{tabular}

De acordo com a Tabela 7, é interessante destacar que, devido à impossibilidade de se obter os valores de limite de liquidez e de plasticidade, o índice de plasticidade não pôde ser calculado, o que caracteriza a cinza pesada como não plástica. Devido à umidade higroscópica da cinza ser $0,1 \%$, isso mostra que o resíduo possui uma massa seca equivalente ao da massa com umidade residual. No caso, essa umidade permanece na amostra, mesmo a deixando secar por um longo período. Tabela 8 .

Os resultados da massa específica e da massa unitária dos materiais utilizados estão apresentados na

Tabela 8: Resultados dos ensaios de caraterização física para os materiais.

\begin{tabular}{l|l|l}
\hline MATERIAL & $\begin{array}{l}\text { MASSA ESPECÍFICA } \\
\left(\mathbf{g} / \mathbf{c m}^{\mathbf{3}}\right)\end{array}$ & $\begin{array}{l}\text { MASSA UNITÁRIA } \\
\left(\mathbf{g} / \mathbf{c m}^{\mathbf{3}}\right)\end{array}$ \\
\hline Brita $19,0 \mathrm{~mm}$ & 2,50 & 1,36 \\
\hline Brita $12,5 \mathrm{~mm}$ & 2,50 & 1,45 \\
\hline Areia natural & 2,69 & 1,41 \\
\hline Areia britada & 2,60 & 1,46 \\
\hline Cinza grossa & 1,59 & 0,65 \\
\hline Cinza fina & 2,20 & 1,04 \\
\hline
\end{tabular}

Conforme dados da Tabela 8, pode-se perceber que as areias possuem massas específicas maiores do que as apresentadas pelas britas, o que indica que as substâncias componentes dos agregados miúdos são mais densas do que as dos graúdos. Também se pode colocar que a brita 19,0 mm possui uma massa unitária menor do que o da brita $12,5 \mathrm{~mm}$ e isso se explica pelo fato de que esta, por ter um aspecto menos graúdo, possui menos vazios entre os grãos. Com relação às areias, essas possuem uma massa unitária maior do que a brita 19,0 mm, pois as mesmas possuem um aspecto mais fino, o que significa uma proximidade maior entre os grãos. No que diz respeito às cinzas, tanto a porção grossa quanto a fina possuem valores de massa específica menores do que os agregados convencionais, o que significa uma leveza maior por parte dos materiais componentes dos resíduos ao se comparar com os outros agregados. A utilização das cinzas no concreto, por exemplo, pode implicar em uma mistura menos densa do que a habitual, o que implicará provavelmente em efeitos nas propriedades mecânicas, como a RCS.

Com relação às composições granulométricas dos materiais, os dados dos agregados e das cinzas estão presentes na Figura 2. Referente a esses dados das cinzas, também foi adicionada a Tabela 9 que mostra o resumo da granulometria para o resíduo, assim, podem ser observados os teores de pedregulho, areia, silte e argila. 


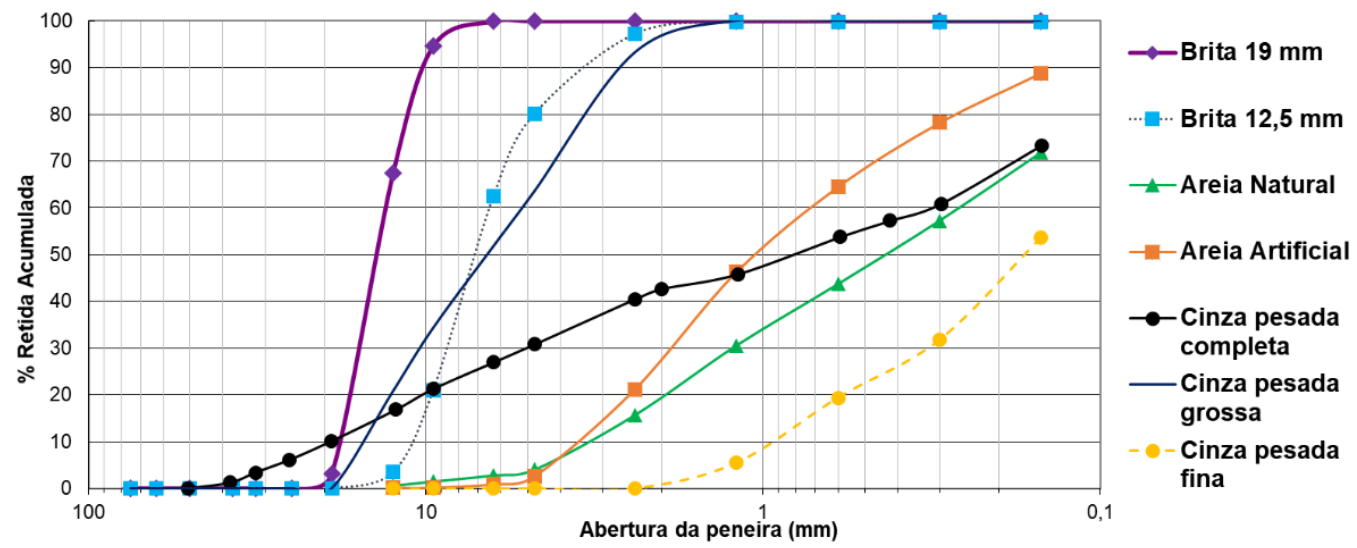

Figura 2: Granulometria dos materiais em função da porcentagem retida acumulada.

Tabela 9: Separação das cinzas, conforme a distribuição granulométrica.

\begin{tabular}{l|l|l}
\hline \multicolumn{2}{l}{ RESUMO DA GRANULOMETRIA PARA A CINZA PESADA } \\
\hline Pedregulho & Acima de $4,8 \mathrm{~mm}$ & $31 \%$ \\
\hline Areia Grossa & $4,8 \mathrm{~mm}-2,00 \mathrm{~mm}$ & $12 \%$ \\
\hline Areia Média & $2,00 \mathrm{~mm}-0,42 \mathrm{~mm}$ & $15 \%$ \\
\hline Areia Fina & $0,42 \mathrm{~mm}-0,074 \mathrm{~mm}$ & $28 \%$ \\
\hline Silte & $0,074 \mathrm{~mm}-0,005 \mathrm{~mm}$ & $12 \%$ \\
\hline Argila & Abaixo de $0,005 \mathrm{~mm}$ & $2 \%$
\end{tabular}

Conforme a Tabela 9, pode-se verificar que a cinza pesada possui, predominantemente, pedregulho $(31 \%)$ e areia fina $(28 \%)$. Isso é uma evidência de que esse resíduo pode vir a substituir o agregado graúdo (brita) ou o miúdo (areia) ao ser incorporado na composição do concreto para BIPs.

\subsection{Resultados e discussão dos ensaios no concreto e nos pavers}

Os resultados dos ensaios de RCS e de absorção de água dos concretos produzidos para os CP's cilíndricos estão apresentados nas Figuras 3 e 5, respectivamente. Os resultados dos ensaios de RCS para os pavers estão mostrados na Figura 4.

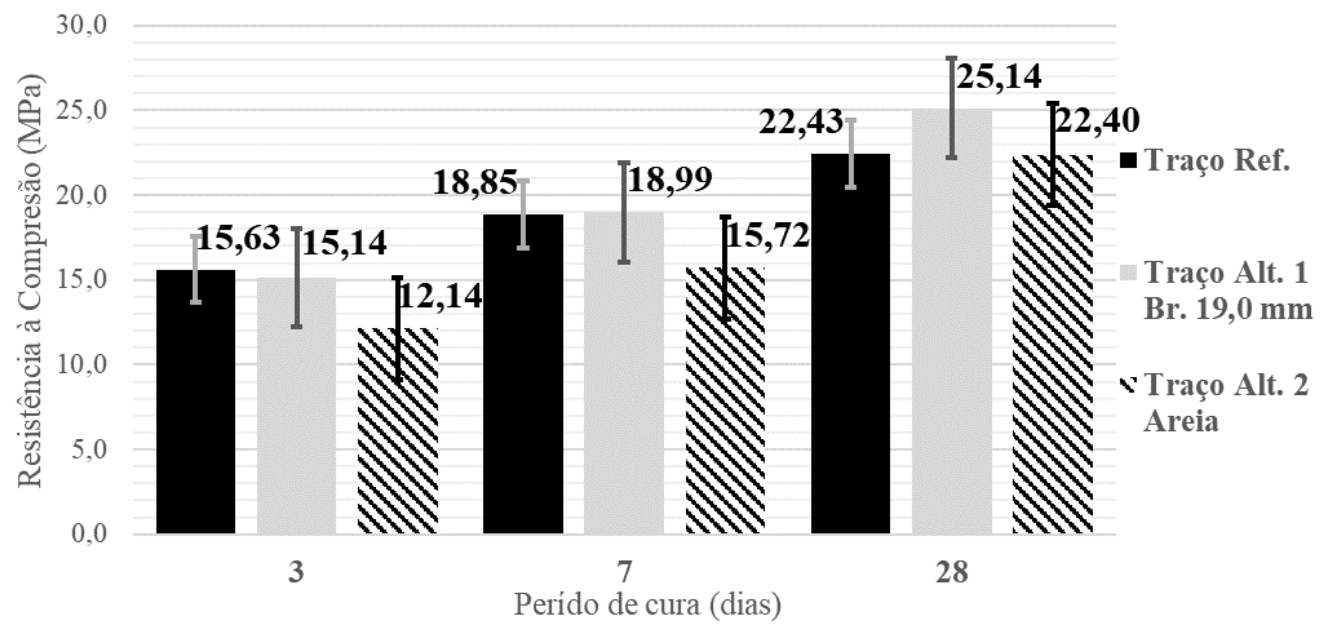

Figura 3: Representação gráfica dos resultados do ensaio de RCS média para CP's cilíndricos. 


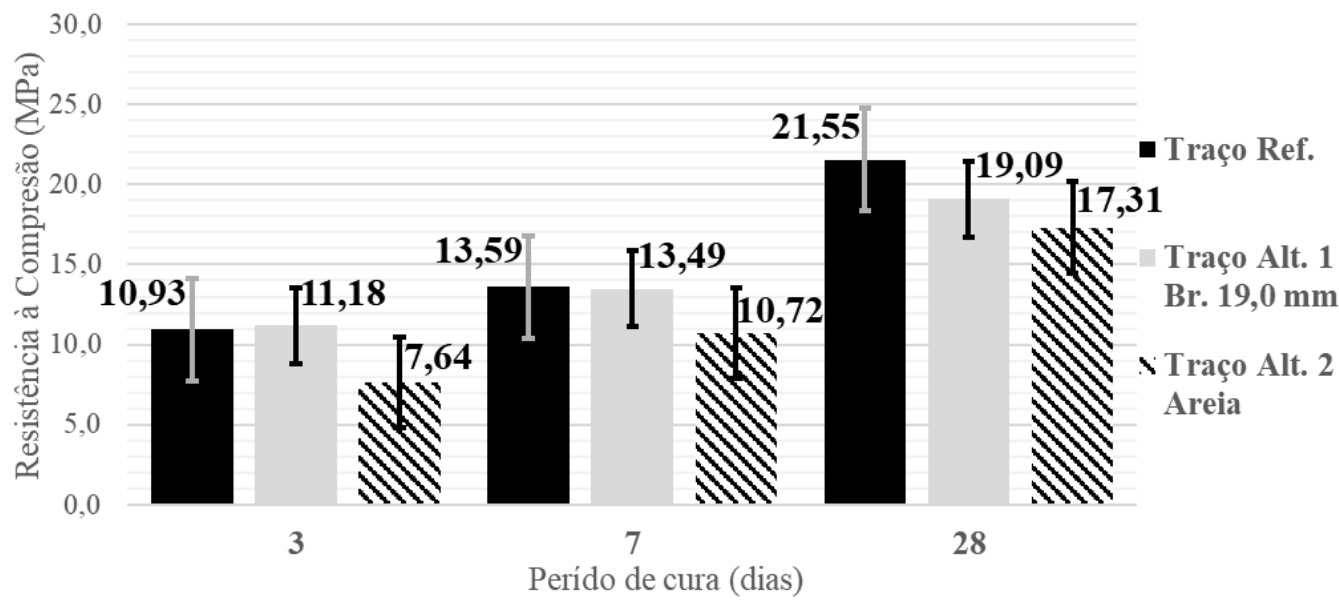

Figura 4: Representação gráfica dos resultados do ensaio de RCS característica para pavers.

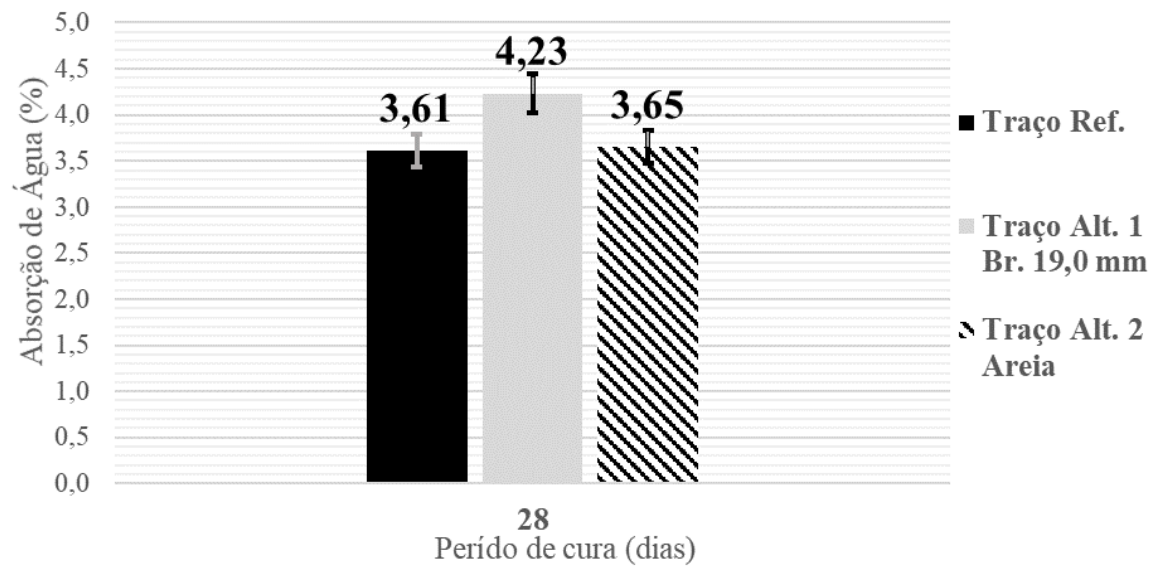

Figura 5: Representação gráfica dos resultados médios do ensaio de absorção de água para CP's cilíndricos.

Analisando as Figuras 3 e 4, destaca-se que todo os valores estão abaixo de $35 \mathrm{MPa}$ ou $28 \mathrm{MPa}$, os quais são os valores mínimos exigidos pela norma ABNT NBR 9781:2013 [6] a depender do tempo de cura. Porém, é possível verificar que o concreto alternativo com a substituição parcial da cinza no lugar da brita 19,0 mm supera a resistência do traço de referência em alguns períodos de cura, o que é interessante. Na Figura 3, aos 7 e 28 dias, os resultados apresentados por esse traço alternativo (18,99 MPa e 25,14 MPa) foram superiores às amostras de referência (18,85 MPa e 22,43 MPa). Isso mostra que, provavelmente, a substituição de $10 \%$, em massa, de brita 19,0 mm por cinza grossa foi benéfica. Já na Figura 4, os blocos do mesmo traço alternativo apresentaram a maior resistência aos 3 dias de cura, porém os pavers de referência foram superiores nos demais períodos, indicando que a presença da cinza pode não ter sido benéfica a longo prazo. Para que ocorra um incremento nas resistências dos blocos alternativos, algo que pode ser feito é o ajuste granulométrico da cinza pesada para se igualar ao da brita $19,0 \mathrm{~mm}$ e da areia, pois a não realização dessa etapa pode ter influenciado nos resultados obtidos.

Uma questão a ser considerada é que, no ensaio de resistência à compressão para blocos, o desempenho dos traços alternativos aos 28 dias de cura foi inferior ao traço de referência. Com relação a isso, pode-se colocar que o intertravamento das cinzas com os demais agregados pode não ter sido tão eficiente ou que a própria resistência do resíduo pode ser inferior aos outros materiais convencionais. Também pode ser investigado o tipo de compactação no concreto, pois o processo mais adequado para a confecção de blocos é o uso de uma máquina de vibro-prensa, a qual consegue compactar o concreto mesmo em estado seco. Na ausência dessa máquina, foi utilizada uma mesa para índice de consistência, o que pode ter feito o concreto dos traços alternativos não ser compactado adequadamente.

Com relação ao requisito de $35 \mathrm{MPa}$, o qual é o valor mínimo de RCS a ser apresentado pelos BIPs aos 28 dias de cura, esse limite mínimo precisa ser melhor investigado. A questão é que, nas normas vigentes de outros países para pavimento intertravado, as especificações para o ensaio de RCS são menos rigorosas. Na África do Sul, a norma SANS 1058:2012 [37] define que os valores mínimos exigidos para a RCS carac- 
terística são $25 \mathrm{MPa}$ para veículos leves e $35 \mathrm{MPa}$ para veículos pesados. Na Austrália, a norma AS/NZS 4456.4:2003 [38] define que os valores mínimos para a RCS característica são $25 \mathrm{MPa}$ para veículos leves, $60 \mathrm{MPa}$ para veículos especiais e $15 \mathrm{MPa}$ para ciclovias e estacionamentos. Percebe-se que a norma brasileira apresenta critérios que podem ser revistos, assim, poderia ser criada uma categoria de pavers para ciclovia ou estacionamento com parâmetros de aceitação mais brandos.

Além da RCS, outros parâmetros podem ser levados em consideração no dimensionamento do pavimento intertravado. Por exemplo, HUURMAN [17] propôs um método de dimensionamento baseado na deformação permanente transversal e longitudinal nas camadas de base e assentamento, considerando a contribuição de todos os componentes do pavimento

No que se refere aos resultados da absorção de água (Figura 5), os valores obtidos para o traço que substitui a areia pela cinza fina são equivalentes aos das amostras de referência. $\mathrm{O}$ traço que substitui o agregado graúdo pela cinza grossa apresentou uma absorção de água ligeiramente superior à do traço de referência. Isso demonstra que a cinza pesada possui uma porosidade maior do que os agregados convencionais, o que provoca uma absorção mais elevada de água por parte do concreto como consequência.

Para averiguar se as substituições de agregados convencionais por cinzas influenciaram significativamente nos resultados dos ensaios de absorção de água e de RCS, tanto dos CP's cilíndricos, como dos pavers, foi realizada a análise ANOVA e o teste de Duncan por meio do software Statistica 7.0. Realizados os testes, foi inserida a Tabela 10 que apresenta se a variável independente, que é o tipo de agregado no traço, em que as cinzas podem ou não estar inseridas, influenciou nas variáveis de resposta consideravelmente. Essas variáveis são a RCS do CP cilíndrico e do paver aos 3, 7 e 28 dias, e a absorção de água do CP cilíndrico aos 28 dias.

Tabela 10: Nível de significância ao se considerar as variáveis de resposta.

\begin{tabular}{|c|c|c|}
\hline $\begin{array}{l}\text { VARIÁVEL } \\
\text { INDEPENDENTE }\end{array}$ & VARIÁVEL DE RESPOSTA & SIGNIFICÂNCIA \\
\hline \multirow{7}{*}{ Tipo de agregado } & RCS do CP com 3 dias & Sim \\
\hline & RCS do CP com 7 dias & Sim \\
\hline & RCS do CP com 28 dias & Sim \\
\hline & RCS do paver com 3 dias & Não \\
\hline & RCS do paver com 7 dias & Não \\
\hline & RCS do paver com 28 dias & Não \\
\hline & Absorção de água do CP com 28 dias & Não \\
\hline
\end{tabular}

De posse dessas informações, serão plotadas as Figuras 6, 7 e 8 que ilustram a variação dos valores médios de RCS e de absorção de água de acordo com o formato do concreto utilizado e com o período de cura. Essas figuras são importantes, para que fique mais claro o quanto os valores médios de cada traço estão próximos ou distantes entre si.

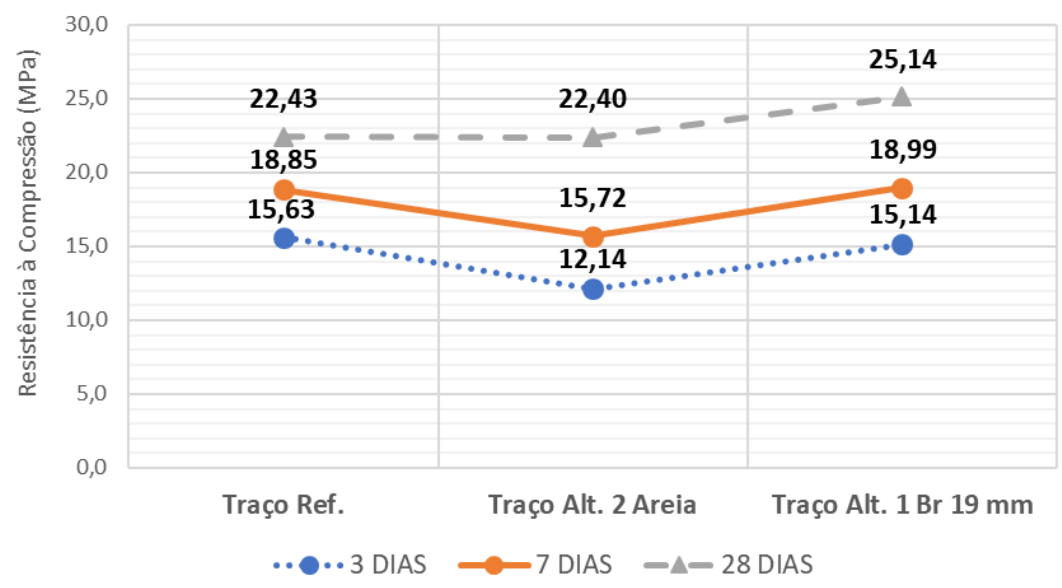

Figura 6: Variação dos valores médios de RCS para CP cilíndrico. 


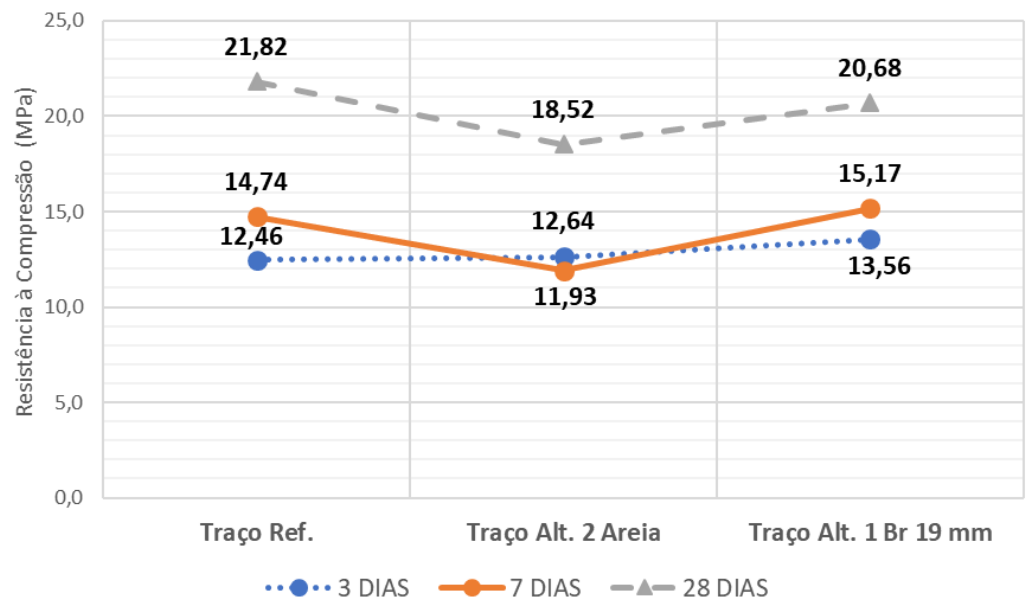

Figura 7: Variação dos valores médios de RCS para paver.

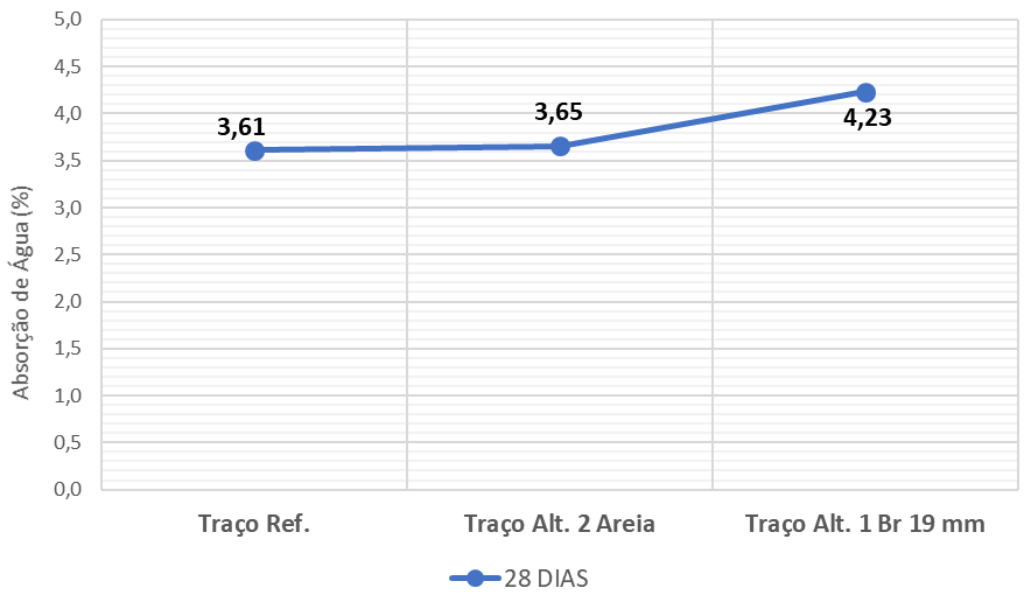

Figura 8: Variação dos valores médios de absorção de água para CP cilíndrico.

De posse dessas informações, pode-se concluir que, para os resultados de RCS para paver em todos os períodos de cura e para a absorção de água em CP cilíndrico aos 28 dias, a mudança de agregado não influenciou sobre os valores dos ensaios significativamente, em que esses não diferiram de forma considerável. Já na RCS para CP cilíndrico em todos os períodos de cura, existe a influência na substituição dos agregados convencionais pelas cinzas. Por exemplo, nos períodos de 3 e 7 dias, o valor referente ao traço alternativo com areia estava menor do que os valores dos outros dois traços do ponto de vista estatístico, o que indica que a substituição de areia por cinzas influenciou negativamente o comportamento do CP nessas idades de cura. Já aos 28 dias, o resultado do traço alternativo com brita 19,0 mm estava maior do que as resistências dos outros dois traços do ponto de vista estatístico, significando que a substituição de brita 19,0 mm por cinzas foi positiva para o CP cilíndrico dessa vez.

Algo importante a ser feito é a comparação dos resultados obtidos com os dados de outras pesquisas feitas na mesma área do conhecimento. Dessa forma, serão utilizados os trabalhos de ERANDI et al. [14] e SENARATNA et al. [15] e os resultados a serem comparados dizem respeito aos ensaios de RCS e absorção de água no período de cura aos 28 dias em blocos paver (Tabela 11). No caso das pesquisas de ERANDI et al. [14] e SENARATNA et al. [15], foram escolhidos os traços alternativos com $25 \%$ e $10 \%$ de substituição em massa do agregado miúdo pela cinza pesada, respectivamente, que são os que mais se aproximam do concreto com $10 \%$ de areia por cinza neste artigo. Apesar dos materiais utilizados serem diferentes, é interessante discutir os efeitos positivos ou negativos da inclusão do resíduo na composição do concreto, com relação às propriedades mecânicas. 
Tabela 11: Diferenças percentuais, com relação aos valores de RCS e absorção de água.

\begin{tabular}{|c|c|c|c|}
\hline \multirow[t]{2}{*}{ PESQUISA } & \multirow[t]{2}{*}{ TRAÇO } & RCS (MPa) & $\begin{array}{l}\text { ABSORÇÃO DE } \\
\text { ÁGUA }(\%)\end{array}$ \\
\hline & & \multicolumn{2}{|c|}{28 Dias } \\
\hline \multirow[b]{2}{*}{ Autores } & Referência & 21,55 & 3,61 \\
\hline & $\begin{array}{l}\text { Alternativo com } \\
10 \% \text { de areia } \\
\text { por cinza }\end{array}$ & $\begin{array}{l}19,09 \\
\rightarrow \text { Diminuição de } \mathbf{1 1 , 4 2 \%}, \\
\text { com relação ao Tr. Ref. } \\
(21,55)\end{array}$ & $\begin{array}{l}3,65 \\
\rightarrow \text { Aumento de } \mathbf{1 , 1 1 \%}, \\
\text { com relação ao Tr. Ref. } \\
(3,61)\end{array}$ \\
\hline \multirow[b]{2}{*}{ ERANDI et al. [14] } & Referência & 68,00 & 5,70 \\
\hline & $\begin{array}{l}\text { Alternativo com } \\
25 \% \text { de areia } \\
\text { por cinza }\end{array}$ & $\begin{array}{l}64,00 \\
\rightarrow \text { Diminuição de } \mathbf{5 , 8 8 \%} \text {, } \\
\text { com relação ao Tr. Ref. } \\
(68,00)\end{array}$ & $\begin{array}{l}5,90 \\
\rightarrow \text { Aumento de } \mathbf{3 , 5 1 \%}, \\
\text { com relação ao Tr. Ref. } \\
(5,70)\end{array}$ \\
\hline \multirow[b]{2}{*}{ SENARATNA et al. [15] } & Referência & 25,50 & 3,20 \\
\hline & $\begin{array}{l}\text { Alternativo com } \\
10 \% \text { de areia } \\
\text { por cinza }\end{array}$ & $\begin{array}{l}23,50 \\
\rightarrow \text { Diminuição de } \mathbf{7 , 8 4 \%}, \\
\text { com relação ao Tr. Ref. } \\
(25,50)\end{array}$ & $\begin{array}{l}3,10 \\
\rightarrow \text { Diminuição de } \mathbf{3 , 1 3 \%} \text {, } \\
\text { com relação ao Tr. Ref. } \\
(3,20)\end{array}$ \\
\hline
\end{tabular}

Com relação à Tabela 11, pode-se perceber que os resultados de RCS nos outros dois trabalhos apresentaram taxas de diminuição, com a incorporação das cinzas, menores do que os valores do presente artigo. Isso pode significar que, apesar do efeito negativo do resíduo em diminuir a resistência do paver, a composição granulométrica da mistura conseguiu incorporar as cinzas de modo que fosse gerado um índice de vazios menos significativo. No que diz respeito à absorção de água, o presente artigo apresentou um aumento menos considerável do que a pesquisa de ERANDI et al. [14], o que é uma vantagem. Uma hipótese a ser considerada é que as cinzas utilizadas nessa pesquisa citada podem possuir uma porosidade mais elevada, o que contribui para o crescimento da absorção de água. É interessante constatar que ocorreu uma diminuição dessa variável no trabalho de SENARATNA et al. [15] com o uso do resíduo, apesar do decréscimo na resistência. Isso é um indicativo de que poderiam ser realizadas substituições com teores maiores de cinzas para testar o comportamento do concreto.

\subsection{Resultados e discussão do dimensionamento do pavimento}

Os materiais utilizados, para esse dimensionamento, foram baseados nos dados da pesquisa de VASCONCELOS [1], em que foi avaliado o emprego de cinza leve no solo utilizado em camadas granulares. Primeiramente, adotou-se um California Bearing Ratio (CBR) de 10\% para o subleito local. Na camada de sub-base, utilizou-se a mistura M3, que é composta por $50 \%$ de solo regional localizado no município de Caucaia no estado do Ceará e por 50\% de cinzas presentes na UTP. Na camada de assentamento e no material de rejuntamento, pelo fato de a norma ABNT NBR 15953:2011 [39] não as especificar quanto ao CBR ou à expansão, decidiu-se utilizar a mistura M1 que é composta por 100\% de solo regional.

É importante citar que, ao final da pesquisa, as misturas utilizadas no trabalho de VASCONCELOS [1] foram aprovadas nos ensaios ambientais de extrato lixiviado e solubilizado. Com relação à mistura M3, essa atende aos requisitos do DNIT para a camada de sub-base por apresentar um CBR de $21 \%$, sendo maior do que $20 \%$, e uma expansão de $0,95 \%$ que é menor do que $1 \%$. Para um melhor entendimento, a Tabela 12 resume as principais características das misturas citadas. 
Tabela 12: Características das misturas.

\begin{tabular}{|c|c|c|c|c|c|c|c|c|}
\hline MISTURAS & $\begin{array}{l}\text { CLASSIFI- } \\
\text { CAÇÃO } \\
\text { HIGHWAY } \\
\text { RESEARCH } \\
\text { BOARD (HRB) }\end{array}$ & $\begin{array}{l}\text { MÓDULO } \\
\text { DE RESI- } \\
\text { LIÊNCIA } \\
\text { MÉDIO } \\
\text { (MPa) }\end{array}$ & $\begin{array}{l}\text { CBR } \\
(\%)\end{array}$ & $\begin{array}{l}\text { EXPAN- } \\
\text { SÃO (\%) }\end{array}$ & $\begin{array}{l}\text { UMI- } \\
\text { DADE } \\
\text { ÓTIMA } \\
(\%)\end{array}$ & $\begin{array}{l}\text { MASSA } \\
\text { ESPECÍ- } \\
\text { FICA SE- } \\
\text { CA MÁ- } \\
\text { XIMA } \\
\left(\mathrm{g} / \mathrm{cm}^{3}\right)\end{array}$ & $\begin{array}{l}\text { LIMITE } \\
\text { DE LI- } \\
\text { QUIDEZ } \\
(\%)\end{array}$ & $\begin{array}{l}\text { ÍNDICE } \\
\text { DE PLAS- } \\
\text { TICIDADE } \\
(\%)\end{array}$ \\
\hline M1 & $A-2-4$ & 161 & 20 & 0,00 & 15,1 & 1,97 & 25 & 7 \\
\hline M3 & - & 149 & 21 & 0,95 & 18,0 & 1,62 & - & - \\
\hline
\end{tabular}

Antes de se partir para o resultado do dimensionamento, é preciso destacar o fato de que está sendo utilizado um método empírico da ABCP [34], ou seja, é uma metodologia que apresenta limitações para a sua aplicação. Dessa forma, é importante que sejam utilizados métodos que permitam a escolha dos materiais para as camadas do pavimento, em função de outros parâmetros, como o módulo de resiliência e deformação permanente. Assim, a utilização de métodos mecanísticos pode ser analisada para este trabalho a posteriori, mas outros experimentos precisam ser realizados para tanto.

Obtidas as informações, procedeu-se para a execução do procedimento empírico da ABCP e a Figura 9 ilustra a seção transversal desse pavimento intertravado dimensionado.

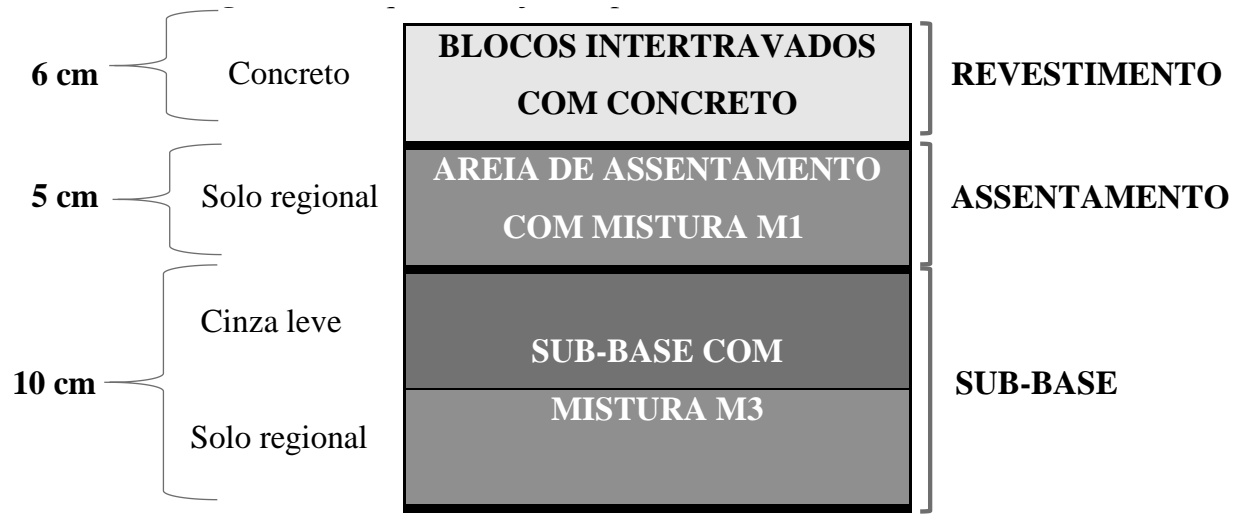

Figura 9: Esquematização do pavimento intertravado dimensionado.

Com as espessuras das camadas determinadas e a área de estacionamento medida, que é de $1624 \mathrm{~m}^{2}$ aproximadamente, foi possível calcular os volumes de materiais a serem utilizados na execução da obra. Com relação ao material de rejuntamento, recorreu-se às composições da tabela de custos da Secretaria da Infraestrutura do Estado do Ceará (SEINFRA - CE) [40]. Descobriu-se que, para a construção de $1 \mathrm{~m}^{2}$ de revestimento de BIPs com dimensões $10 \mathrm{~cm} \div 20 \mathrm{~cm} \div 6 \mathrm{~cm}$ (largura $\div$ comprimento $\div$ espessura), é preciso 0,15 $\mathrm{m}^{3}$ desse material. Dessa forma, a Tabela 13 apresenta os volumes de materiais necessários para a construção do pavimento intertravado. É necessário que esses dados sejam apresentados, pois colabora com o intuito de fornecer uma finalidade útil para as cinzas, o que vai de encontro com a viabilidade ambiental do uso desse resíduo.

Tabela 13: Relação dos volumes dos materiais em suas respectivas camadas no pavimento.

\begin{tabular}{l|l|l|l|l}
\hline CAMADAS & MATERIAIS & ESPESSURA $(\mathbf{c m})$ & ÁREA $\left(\mathbf{m}^{2}\right)$ & VOLUME $\left(\mathbf{m}^{3}\right)$ \\
\hline \multirow{2}{*}{ Sub-base } & Cinza leve & \multirow{2}{*}{$10 \mathrm{~cm}$} & & 81,20 \\
\cline { 2 - 3 } & Solo regional & & \multirow{2}{*}{1624} & 81,20 \\
\cline { 1 - 2 } Assentamento & Solo regional & $5 \mathrm{~cm}$ & & 81,20 \\
\hline Revestimento & Concreto & $6 \mathrm{~cm}$ & 97,44 \\
\hline Rejuntamento & Solo regional & - & & 243,60 \\
\hline
\end{tabular}


No caso da cinza leve, o volume de $81,2 \mathrm{~m}^{3}$ é equivalente a 130 toneladas aproximadamente, já, com relação ao volume de $97,4 \mathrm{~m}^{3}$ de concreto, isso corresponde a cerca de 211,1 toneladas da mistura. Ao se utilizar o traço com substituição de $10 \%$ de brita $19,0 \mathrm{~mm}$ por cinza grossa para a produção dos pavers, ocorre o consumo de 1,18 toneladas do resíduo. No caso do uso do traço com substituição de $10 \%$ de areia por cinza fina, esse consumo aumenta para 11,01 toneladas.

\section{CONCLUSÕES}

A principal contribuição desta pesquisa foi verificar a possibilidade do aproveitamento das cinzas de carvão mineral, por meio de amostras superficiais obtidas na UTP, para a fabricação de blocos intertravados de concreto na área de pavimentação.

A utilização do traço alternativo com substituição de $10 \%$ de brita 19,0 mm por cinza grossa apresenta-se como uma potencial alternativa à produção de pavers, devido aos resultados do mesmo serem mais próximos à mistura de referência. Com relação à resistência à compressão, é possível observar que os resultados são inferiores aos mínimos de $35 \mathrm{MPa}$ ou $28 \mathrm{MPa}$ colocados na norma ABNT NBR 9781:2013 [6]. De posse dessa informação, é possível destinar os pavers com essa dosagem para áreas com menores solicitações de tráfego, como ciclovias. Contudo estima-se que seja possível conseguir pavers com resistência superior a 35 $\mathrm{MPa}$, desde que sejam feitas modificações no traço de referência. Uma hipótese a ser testada é aumentar o consumo de cimento, mas esse acréscimo deve ser feito, considerando que isso acarretará o aumento do custo da produção do concreto. Além disso, existem indícios de que a norma ABNT NBR 9781:2013 [6] apresenta critérios que podem ser revistos, para que os blocos paver estejam dentro das especificações com uma maior facilidade a depender do campo de aplicação dos mesmos blocos.

Dessa forma, dada a possibilidade de substituição de materiais convencionais de construção por resíduos de termelétrica (custo zero de aquisição), é esperado, também, que a estrutura proposta do pavimento intertravado apresente custos abaixo dos pavimentos usuais construídos no estado do Ceará.

Assim, de uma maneira geral, conclui-se que o reaproveitamento das cinzas na produção de pavimentos intertravados, constituídos pelas camadas granulares e pelo revestimento em blocos de concreto, pode ser uma alternativa ambientalmente satisfatória e aceitável do ponto de vista técnico.

\section{AGRADECIMENTOS}

Os autores agradecem às empresas OCS e Cimento Apodi pela disponibilização dos agregados e do cimento para esse estudo. Além disso, é importante destacar a colaboração da EDP, no âmbito do projeto de Cooperação EDP/UFC/Fundação de Apoio a Serviços Técnicos, Ensino e Fomento de pesquisas (ASTEF) Nº1/2018, pelo fornecimento das cinzas e financiamento da pesquisa. Também é preciso frisar a importância dos locais de realização dos ensaios na UFC, como o Laboratório de Mecânica dos Pavimentos, Laboratório de Materiais de Construção Civil e Laboratório de Mecânica dos Solos e Pavimentação.

\section{BIBLIOGRAFIA}

[1] VASCONCELOS, S.D., Avaliação das cinzas de carvão mineral produzidas em usina termelétrica para construção de camadas de pavimentos, Tese de M. Eng., PETRAN/UFC, Fortaleza, CE, Brasil, 2018.

[2] MALLMANN, J. E. C.; ZWONOK, O. "Panorama dos resíduos da combustão do carvão mineral e características químicas e físicas das cinzas de fundo das usinas do Rio Grande do Sul", In: anais do III Congresso Brasileiro de Carvão Mineral, Gramado, 2011.

[3] BARROS, K.S., "Estudo de cinzas volantes de uma termelétrica da região metropolitana de Fortaleza-CE para aplicação em camadas granulares de pavimentos”, Tese de M. Eng., PETRAN/UFC, Fortaleza, CE, Brasil, 2015.

[4] KNIESS, C.T., "Desenvolvimento e caracterização de materiais cerâmicos com adição de cinzas pesadas de carvão mineral”, Tese de D. Sc., UFSC, Florianópolis, SC, Brasil, 2005.

[5] ZWONOK, O., et al., Identificação dos usos possíveis (estado da arte) para as cinzas de carvão mineral de termelétricas brasileiras, In: Relatório Técnico do CIENTEC, Porto Alegre, 1996.

[6] ASSOCIAÇÃO BRASILEIRA DE NORMAS TÉCNICAS, NBR 9781: Peças de concreto para pavimentação - Especificação e métodos de ensaio, Rio de Janeiro, ABNT, 2013.

[7] FERNANDES, I., Blocos e pavers: produção e controle de qualidade, 7 ed., Ribeirão Preto, Treino Assessoria e Treinamentos Empresariais Ltda, 2016. 
[8] SHARMA, M. et al., "Influence of bacteria on compressive strength of rubber mould paver block", International Journal of Constructive Research in Civil Engineering, v. 3, n. 1, pp. 11-18, 2017.

[9] SOUZA, A.M.P.F.F.C., "Pavimento intertravado de concreto com adição de resíduos de óxido de alumínio - sínter", Monografia em Engenharia Civil, USF, Bragança Paulista, SP, Brasil, 2011.

[10] GUERRA, A.N.L.P. "Caracterização e utilização de rejeito de minério de ferro pellet feed em pavimentos de blocos intertravados de concreto", Tese de M. Eng., UFMG, Belo Horizonte, MG, Brasil, 2014.

[11] GUPTA, A., TIWARI, A., "Effect on mechanical properties of paver block consist crusher stone dust as fine aggregate with inclusion of steel fiber", International Journal for Research in Applied Science \& Engineering Technology, v. 4, n. 10, pp. 529-535, Oct. 2016.

[12] GAWATRE, D.W. et al., "Manufacture of paver block using partial replacement of construction and demolition concrete waste", International Journal of Pure and Applied Research in Engineering and Technology, v. 4, n. 9, pp. 11-18, May 2016.

[13] NATARAJA, M.C., DAS, L., "A study on the strength properties of paver blocks made from unconventional materials", International Organization of Scientific Research - Journal of Mechanical and Civil Engineering, v. 4, n. 10, pp. 01-05, 2006.

[14] ERANDI, N.G.N. et al., "Use of bottom ash as fine aggregate in manufacturing concrete paving blocks", In: proceedings of the II Advances in Civil and Environmental Engineering Practices for Sustainable Development, pp. 69-74, Sri Lanka, 2013.

[15] SENARATNA et al., "Utilization of bottom ash as a construction material", In: proceedings of 4th International Conference on Structural Engineering and Construction Management, pp. 82-93, Sri Lanka, 2013.

[16] CRUZ, L.O.M., "Pavimento intertravado de concreto: estudo dos elementos e métodos de dimensionamento", Tese de M. Sc., COPPE/UFRJ, Rio de Janeiro, RJ, Brasil, 2003.

[17] HUURMAN, M., "Resilient behaviour of concrete block pavements and the granular materials used in the substructure", In: proceedings of the V International Concrete Block Paving Conference, pp. 239-251, Tel-Aviv, 1996.

[18] BABA, T. et al., "Evaluation of bearing capacity of interlocking block pavements using HFWD", In: proceedings of the VI International Concrete Block Paving Conference, pp. 61-70, Tokyo, 2000.

[19] ASSOCIAÇÃO BRASILEIRA DE NORMAS TÉCNICAS, NBR 15900-1: Água para amassamento do concreto - Parte 1: Requisitos, Rio de Janeiro, ABNT, 2009.

[20] DEPARTAMENTO NACIONAL DE ESTRADAS DE RODAGEM, ME 041: Solos - preparação de amostras para ensaios de caracterização, Rio de Janeiro, DNER, 1994.

[21] DEPARTAMENTO NACIONAL DE ESTRADAS DE RODAGEM, ME 051: Análise granulométrica, Rio de Janeiro, DNER, 1994.

[22] DEPARTAMENTO NACIONAL DE ESTRADAS DE RODAGEM, ME 082: Solos - determinação do limite de plasticidade, Rio de Janeiro, DNER, 1994.

[23] DEPARTAMENTO NACIONAL DE ESTRADAS DE RODAGEM, ME 093: Solos - determinação da densidade real, Rio de Janeiro, DNER, 1994.

[24] DEPARTAMENTO NACIONAL DE ESTRADAS DE RODAGEM, ME 122: Solos - determinação do limite de liquidez - método de referência e método expedito, Rio de Janeiro, DNER, 1994.

[25] ASSOCIAÇÃO BRASILEIRA DE NORMAS TÉCNICAS, NBR 10005: Procedimento para obtenção de extrato lixiviado de resíduos sólidos, Rio de Janeiro, ABNT, 2004.

[26] ASSOCIAÇÃO BRASILEIRA DE NORMAS TÉCNICAS, NBR 10006: Procedimento para obtenção de extrato solubilizado de resíduos sólidos, Rio de Janeiro, ABNT, 2004.

[27] ASSOCIAÇÃO BRASILEIRA DE NORMAS TÉCNICAS, NBR NM 53: Agregado graúdo - Determinação da massa específica, massa específica aparente e absorção de água, Rio de Janeiro, ABNT, 2009.

[28] ASSOCIAÇÃO BRASILEIRA DE NORMAS TÉCNICAS, NBR NM 52: Agregado miúdo - Determinação da massa específica e massa específica aparente, Rio de Janeiro, ABNT, 2003.

[29] ASSOCIAÇÃO BRASILEIRA DE NORMAS TÉCNICAS, NBR NM 45: Agregados - Determinação da massa unitária e do volume de vazios, Rio de Janeiro, ABNT, 2006. 
[30] ASSOCIAÇÃO BRASILEIRA DE NORMAS TÉCNICAS, NBR NM 248: Agregados - Determinação da composição granulométricas, Rio de Janeiro, ABNT, 2003.

[31] DEPARTAMENTO NACIONAL DE INFRAESTRUTURA DE TRANSPORTES, ME 064: Pavimento rígido - Determinação da consistência do concreto pelo consistômetro VeBe - Método de ensaio, Rio de Janeiro, DNIT, 2004.

[32] ASSOCIAÇÃO BRASILEIRA DE NORMAS TÉCNICAS, NBR 5739: Concreto - Ensaio de compressão de corpos-de-prova cilíndricos, Rio de Janeiro, ABNT, 2007.

[33] ASSOCIAÇÃO BRASILEIRA DE NORMAS TÉCNICAS, NBR NM 67: Concreto - Determinação da consistência pelo abatimento do tronco de cone, Rio de Janeiro, ABNT, 1998.

[34] ASSOCIAÇÃO BRASILEIRA DE CIMENTO PORTLAND, ET - 27: Pavimentação com peças prémoldadas de concreto, São Paulo, ABCP, 1998.

[35] LOPES, L.S.E. et al., "Análise do comportamento de um solo estabilizado com cinzas de carvão mineral para aplicação em camadas de base de pavimentos", Revista Pavimentação, v. 36, pp. 63-82, 2015.

[36] BAIRD, C., Quimica Ambiental, 2a ed., Porto Alegre, Bookman, 2002.

[37] THE SOUTH AFRICAN BUREAU OF STANDARDS, SANS 1058: Concrete paving blocks, South Africa, SABS, 2012.

[38] STANDARDS AUSTRALIA, AS/NZS 4456.4: Masonry units and segmental pavers and flags - Methods of test - Determining compressive strength of masonry units, Australia, 2003.

[39] ASSOCIAÇÃO BRASILEIRA DE NORMAS TÉCNICAS, NBR 15953: Pavimento intertravado com peças de concreto - Execução, Rio de Janeiro, ABNT, 2011.

[40] SECRETARIA DA INFRAESTRUTURA DO ESTADO DO CEARÁ, Tabela de Custos versão 024, Fortaleza, SEINFRA - CE, 2017.

\section{ORCID}

Webert Brasil Cirilo da Silva Suelly Helena de Araújo Barroso Antônio Eduardo Bezerra Cabral https://orcid.org/0000-0002-4712-0582

https://orcid.org/0000-0003-0580-8706

https://orcid.org/0000-0001-6394-1164 